\title{
Highlighting Difficulties in Idiomatic Translation
}

\author{
John Mervyn Evjen \\ Department of Modern Languages and Cultural Studies, University of Alberta, Edmonton, Alberta \\ Corresponding author: evjen@ualberta.ca
}

\section{ABSTRACT}

Idioms are fixed phrases with little to no possible syntactic reconfiguration, whose lexemes are not representative of the meaning they convey in any given language. Their complexity is rooted in deep semantic structures from ages of cultural history. In translation, idioms pose great difficulty due to their innate dichotomous nature and deep cultural roots. For an idiom to be translated from the source language into the target language, an equivalent idiom must be found in the target language in order for the translated idiom to have the same effect on the audience. This paper examines three English and German idioms in comparison to determine what allows for equivalency between translated idioms. Between the three levels of equivalence, strong, weak, and zero equivalence, there are different factors that add to the complexity of translation and their counterparts in translation. In this paper, I explore three levels of idiomatic equivalence and discuss how these three levels are different from each other.

Idioms pose some of the most difficult translation problems to the practice and theory of translation. Mildred Larson (20) and Mona Baker (67) define idioms as fixed collocations whose meaning is different from the meaning conveyed by the individual words. As a result, idioms rarely remain culturally relevant if translated verbatim. The difficulty of translating idioms does not stem from the grammatical or semantic complexities; these complexities merely add a layer to culturally metaphorical meaning. The needed wealth of cultural and metaphorical meaning of idioms renders translating idioms extremely challenging
(Takacs 42). Larson (22) suggests translators must understand the true meaning of the idiom before the translation can occur. In this paper, I will explore different idioms translated between German and English and show how equivalence may be used to compare and further contrast the cultural meanings for the intended audience. Through comparing literal translations of the idioms and determining cultural connotations, this essay will contrast idioms in English and their German translations to reveal major issues while translating idioms and proposing solutions to these issues. 
Due to the extreme difficulty of translating idioms, some scholars have argued that culturally-specific relevance alone should deter the translation of idioms (Benjamin 75). Translating idioms literally would result in the loss of the language's semantic and aesthetic beauty (Takacs 44). In her course book, In Other Words, Baker states that even native speakers are severely restricted while using idioms (Baker 67). If native speakers, let alone translators, do not follow these restrictions, the idiomatic language becomes unnatural and thus the translation erroneous. Common knowledge between the speaker and listener allows for the mutual understanding of idioms, but foreign translators may not have adequate idiomatic sensitivity (Matthews 152; Osadnik \& Świeściak 8). Due to the inability to gain native speakers' idiomatic sensitivity, organisations such as the Translators' Guild of Great Britain forbid translators from translating into non-native languages (Baker 68). Although the challenges presented by translating idioms seem to overwhelm its feasibility, translators can surmount these challenges by using the correct theoretical lens.

All idioms have specific source-cultural meaning that translators must transfer or substitute with target-culturally relevant information of the same nature (Matthew 152). George Steiner's essay, "The Hermeneutic Motion", shows the translator may have to take the "treasure" from the text forcibly, which is to say that the meaning of the text is not easily retrievable from the surface level of the text (157). In this case, the translator must understand the depth of the idiom within the text and translate it into the target language using the same level of analysis. Looking at Robert J. Matthews' (160) notion of translation, the translation must transfer this meaning from one language to the other in a naturalizing way (Larson, 143).

In her book Meaning-based Translation, Larson (252) asserts that idioms contain dead metaphors. Dead metaphors are metaphors that the reader does not need to visualise in order to understand them, as opposed to live metaphors, which the reader has to actively visualise. Instead, these metaphors "have lost their metaphoricity over time and now exist in the speakers' mental lexicons as stock formulas" such that "speakers no longer view face of the clock or arm of a chair as metaphoric (Gibbs 98)." Dead metaphors represent a semantic field, rather than a lexical set (Baker 16), and thus the translator does not need to transfer metaphor itself into the target language, rather the semantic value behind the metaphor (Matthews 152). These dead metaphors ultimately form what Csilla Takacs calls an "underlying conceptual metonymy" (43) between languages. Baker, Matthews, Steiner and Takacs all argue that there is a central element, which needs to be equivalent between the source and the target text. The question remains: how can a translator be certain that the "underlying conceptual metonymy" is equivalent in the target text?

The fascination of translating idioms is that, although there may be zero equivalence, there is great similarity in the human experience (Takacs 42). Translator-scholars such Matthews and Steiner infer that translators should search for interlingual similarity by way of taking the treasure of the text and transferring it to the other culture. Takacs's "underlying conceptual metonymy" helps pinpoint what the translator should be attentive to while translating (43). Despite finding an idiom's core interlingual meaning, equivalence is an ambiguous term which needs proper defining.

To place my essay in the literature, I will rely on Vanessa Leonardi's and Alanna Supersad's work on equivalence heavily to define equivalence in this paper. Leonardi argues that linguistic equivalence pales in comparison to semantic equivalence as semantic equivalence retains meaning rather than source language authenticity (Equivalence in Translation: Between Myth and Reality). Supersad's argument for infinite definitions of equivalence demonstrates that an intersection of equivalence models is necessary to suitably define equivalency between idioms (62). Both Leonardi and Supersad 
draw their conceptions of equivalence from Eugene Nida's dynamic equivalence model to make their arguments that translators should strive for semantic equivalence (149).

Nida presents two notions of equivalence in his paper, "Principles of Correspondence," namely, formal and dynamic equivalence. Formal equivalence allows the reader to identify as closely with the source-language context as possible and lets the reader gain deep and authentic insights into the source culture (149). Dynamic equivalence, on the other hand, contains the principle of "equivalent effect," the naturalness of expression (151). Using dynamic equivalence, the reader must not understand the source-language culture; the reader only needs to understand the core meaning of the text, allowing for a fascinating translation process (153). Nida's dynamic equivalence suffices the question of how the main idea of the idiom should be translated. Using Nida's "dynamic equivalence" and other theoretical lenses, the implications of the strength of equivalence on translation will be delineated

Strong equivalence translations show how languages and cultures can be similar. In examples of strong equivalence, there is no difference in grammatical structure despite the difference in cultural context. With the example, "We are all in the same boat," and the German idiom, "Wir sitzen alle im selben Boot," (we sit all in the same boat) the similarities between the languages and cultures are readily identifiable.

Both idioms are nearly identical in both languages in terms of structure and semantics. Comparing the idioms side-by-side, the grammar and words of both are almost identical. Additionally, either audience can understand the idiom's meaning because of the mutual understanding (Osadnik \& Świeściak 8): being on a boat limits one's options and two people on the same boat have the same options. The attentive translator would reason that the concept is a Western theme and, thus given the theme's universality in the Western world and near equality of structures, a literal translation of idiom becomes a tempting solution. The literal translation, in this case, would work structurally, but would not account for the naturalness of the language (Larson 143). Strong equivalence between translations shows how literal translations can be unnatural to the target audience.

In 2010, the premier of Baden-Württemberg, Günter Oettinger, gave a speech at an American university, in which he used a literal translation of the German idiom. Soon after he proclaimed, "...we are all sitting in the same boat," his speech encouraged much laughter and later became a German internet sensation (Frankfurter Allgemeine Zeitung). The humour in Oettinger's literal translation stems from the unnaturalness of the language (Larson 143). This example evinces the effects that a non-naturalised, non-idiomatic translations may have on the target audience.

According to Nida, there is very little that needs to change to transfer the correct meaning between languages, as the source language structure is nearly identical to the target language structure (151). "We are all sitting," albeit grammatically correct, is not natural in English. Naturalisation needs to be considered while translating this idiom (Larson 143). Translating 'sitzen' to "are" or vice versa naturalises the language and furthermore prevents awkward, unnatural, and potentially humorous translation. The strong equivalence between the two idioms allows for a relatively easy translation, but weak equivalence causes other problems, a concept to be explored below.

Weak equivalence is an ambiguous category between strong equivalence and zero equivalence. There are few criteria and there is even less clarity as to what constitutes weak equivalence and what separates weak from strong and zero equivalence. This ambiguity allows for infinite definitions of weak equivalence, which itself can lead to misunderstandings (Supersad 62). For the purpose 
of this essay, a translation with weak equivalence generally contains similar grammatical structure and semantic fields. Without structural similarity, one could argue that the translation has zero equivalence to the source text, as they bear no visual resemblance. It is important that the translation and source text retain similar structure in that a similar metaphor is used. The English animal idiom, "a bird in the hand is worth two in the bush," or, "a bird in the hand beats two in the bush," and its German counterpart, "Besser den Spatz in der Hand als die Taube auf dem Dach,"(better the Sparrow in the hand than the pigeon on the roof) fulfil this paper's criteria for weak equivalence by using the same metaphor. These two idioms also have structural similarity. This example of weak equivalence between English and German idioms shows how much a shared dead metaphor's cultural meanings can vary.

While comparing the two idioms, the most noticeable distinction is the differentiation between bird species. In the English idiom, the superordinate "bird" is used rather than the hyponyms "Spatz" (Sparrow) and "Taube" (Pigeon). The cultural importance of "Spatz" and "Taube" seem to differ between the languages, where the English culture does not seem to put much weight on the difference between the two birds. The importance of size to the German audience separates the idioms by their respective cultural connotations. This differentiation between bird species infers the German audience may attribute a considerable value to the cliché, "bigger is better."

In contrast, the English idiom connotes that amount may be more important than size. The species, size and appearance of the bird are not seen as important by the English audience in that the idiom refers to two birds rather than species. The number of birds is the relevant cultural aspect, so the English audience may agree with the cliché, "more the merrier." Contrasting these two idioms leads to the discovery of deep cultural structures which aid a translator in deciding how to translate an idiom. If the idiom were translated into English from German literally, the English audience may ask: why are the pigeon and sparrow so important in this situation? Conversely, a German speaker might ask: why would I even go into the bush to grab two birds when I do not even know what the birds look like? The differences in culture may prove problematic in translation, but the translation can still be accomplished by transferring cultural relevancy. In the instance of weak equivalence, using Larson's notion of live and dead metaphors can show how a translation can be accurate (252).

These differences in translation create live metaphors rather than dead metaphors because the meaning behind the metaphor is not unique to that metaphor. The translations show no signs of acts of naturalisation because of the superordinate in German. "Vogel" could still be used and the meaning would still be relevant. The idiom would not sound any less natural if it were "Besser den Vogel in der Hand als den Vogel auf dem Dach" (better the bird in the hand than the bird on the roof). The substitution of the hyponyms for the superordinate would create a live metaphor rather than an easier-to-understand dead metaphor (252). Clearly, a specific cultural meaning has worked its way into the idiom and this cultural meaning is identified in the dead metaphor (Osadnik \& Świeściak 8). The idiom uses dead metaphors because they are defined in colloquial language and not by their lexical, dictionary, definition.

The final idiom discussed in this paper is "don't cry over spilt milk." This food idiom has no full equivalent in German. The German language offers a range of translations for the English idiom, but this paper will focus on one translation to be specific: "Geschechen ist Geschechen" (occurrences are occurrences). Based solely on syntax, the scholar notices that the sentences syntactic structures do not share any similarities. The similarities between the English and German equivalents lie in the semantic meaning, but they are indeed limited to the lexical definitions of their parts. 
Focusing on semantic meaning when saying, "don't cry over spilt milk," the speaker implies that the milk is irrecoverable from its spilt state. The spilt state is unchangeable and irreversible, leaving any reaction to its unchangeable state illogical or unbeneficial to the situation. "Geschechen ist Geschechen" refers to the unchangeable state of what the "Geschehen" (occurrences) are. Both idioms share a sense that what has been done cannot be reversed and it should not be discussed further. Both idioms ultimately denote that what has occurred is what has occurred. Takacs describes this sense as the "underlying conceptual metonymy" between the two languages (43). This analysis shows that, regardless of the few similarities the idioms, they contrast one another because of the different cultural connotations based on target audience.

The English saying, "don't cry over spilt milk," refers to a childish tone. The idiom's tone suggests the idiom is usually used to teach children not to fret over things they cannot change, such as unrecoverable spilt milk. Being that it is didactic in use and meaning unlike the German idiom, there is no easily interpretable audience for the German idiom. One could reason that the idioms originate from the Pontius Pilate's claim of innocence: 'What I have written I have written' (King James Version, John 19:22) or in German, "Was ich geschrieben habe, das habe ich geschrieben" (Luther Bibel 1545, Johannes 19:22). Frequent use of the German Bible verse could easily result in the phrase's development into "Geschrieben ist Geschrieben" and finally into "Geschehen ist Geschehen." As shown by the difference in usage, the main difference between the English and German idioms lies in the audience. In the case of zero equivalence, the effective translator extracts the "underlying conceptual metonymy" (Takacs, 43) from the idiom. The translator must find the treasure of the text and put that into the target language in relation to the target audience (Steiner 157). The core concept should be taken and culturally-appropriated to create a translation to which the target audience can relate.

This essay has contrasted different idioms between German and English and shown how equivalence may be used to compare and contrast cultural audience. With the example of "Wir sitzen alle im selben Boot," it becomes clear that although literal translation can sometimes convey the same meaning, words need to be naturalised. With "Besser den Spatz in der Hand, als die Taube auf dem Dach," the people's use of a dead metaphor is most important to how the idiom is used (Osadnik \& Świeściak 8), and Matthew's notion of transfer is the only way to have a dynamic equivalence (156). "Don't cry over spilt milk," shows us how Takacs' concept of an "underlying conceptual metonymy" can help shape a translation (43) while considering the audience. Nida's dynamic equivalence shows how the translator needs to account for the culture in translating idioms. Baker raises the question of whether we should not just strive for pragmatic equivalence (230). The treasure of the text may be the effect of the work rather than the words and grammatical structures, which is the future path of understanding translation in a way that is more inclusive of the target audience. 


\section{Works Cited}

"„We are all sitting in one boat"." Günther Oettinger, Frankfurter Allgemeine Zeitung, 28 Jan. 2010, www.faz.net/aktuell/gesellschaft/menschen/guenther-oettinger-we-are-all-sitting-in-oneboat-1907523.html.

Baker, Mona. In Other Words: A coursebook on translation. 2nd ed., Routledge, 2011.

Benjamin, Walter. "The Translator's Task." The Translation Studies Reader, edited by L Venuti, 3rd ed., Routledge, 2012, pp. 75-83.

Gibbs, Raymond W. "Idiomaticity and Human Cognition." Idioms: Structural and Psychological Perspectives, edited by Martin Everaert et al., Psychology Press, 2014, pp. 97-116.

Matthews, Robert. J. "What Did Archimedes Mean by xuøós?" Difference in Translation, edited by Joseph F. Graham, Cornell University Press, 1985, p. Ithaca and London.

Larson, Mildred. L. Meaning-based Translation: A guide to Cross-language Equivalence. University Press of America, 1984.

Larson, Mildred. Meaning-Based Translation: A Guide to Cross-Language Equivalence. University Press of America, 1998.

Leonardi, Vanessa. Equivalence in Translation: Between Myth and Reality. Translation Journal, 19 May 2014, translationjournal.net/journal/14equiv.htm

Nida, E. "Principles of Correspondence." The Translation Studies Reader, edited by L Venuti, 3rd ed., Routledge, 2012, pp. 141-155.

Osadnik, Waclaw. M., and A. Świeściak, editors. Studies in Translation: History and Theory. Katowice, 2015.

Steiner, George. "The hermeneutic Motion." The Translation Studies Reader, edited by L Venuti, 3rd ed., Routledge, 2012, pp. 43-63.

Takacs, Csilla. "The Fascination of Translating Idioms." Bulletin of the Transilvania University of Brasov, Series IV: Philology \& Cultural Studies, vol. 8, no. 2, July 2015, pp. 41-54. EBSCOhost, login. ezproxy.library.ualberta.ca/login?url=http://search.ebscohost.com/login.aspx?direct=true \&db=a 9h\&AN=112128736\&site=eds-live \&scope $=$ site. . 